\title{
Papel etiológico de los virus en la enfermedad periodontal
}

\author{
ECHEVERRÍA A* \\ VIGNOLETTIF* \\ FABRIZIS** \\ MATESANZ P***
}

Echeverría A, Vignoletti F, Fabrizi S, Matesanz P. Papel etiológico de los virus en la enfermedad periodontal Av Periodon Implantol. 2007; 19, 2: 91-99.

\begin{abstract}
RESUIMIEN
El objetivo de esta revisión es presentar la evidencia disponible que relaciona la infección por virus con el desarrollo de periodontitis. Esta relación se ha visto con los virus de la familia herpes, sobretodo el citomegalovirus humano (CMV) y el virus Epstein-Barr (VEB), así como con el virus de la inmunodeficiencia humana (HIV).

Las infecciones por herpesvirus generalmente sucede en dos fases, durante la primoinfección la clínica suele ser leve o asintomática y a esta le sigue una fase asintomática en la que el virus se encuentra en estado de latencia. Dicho estado se verá interrumpido esporádicamente por periodos de activación en los que se produce una replicación viral y posiblemente se dé una manifestación de la enfermedad que explicaría, en parte, el progreso en episodios de la enfermedad periodontal. De hecho, algunas de las causas que llevan a la reactivación del virus también se consideran factores de riesgo de la enfermedad periodontal y podrían relacionar a ambas patologías.
\end{abstract}

\section{PALABRAS CLAVE}

Herpesvirus, citomegalovirus humano, virus Epstein-Barr, virus herpes simple, enfermedad periodontal, patogénesis

Fecha de recepción: Octubre 2006.

Fecha de aceptación: Noviembre 2006.

\section{INTRODUCCIÓN}

La periodontitis es una enfermedad infecciosa en cuya etiología las bacterias tienen un papel esencial pero no único. Son numerosos los estudios que han demostrado una relación causal entre el acúmulo de placa y el desarrollo de gingivitis o inflamación gingival. Sin embargo, a pesar de la evidencia de relación causal entre bacterias y enfermedad periodontal, existe una gran diversidad en la expresión de esta patología. En función de la edad, la raza, la situación socio-económica, las condiciones sistémicas o los hábitos del individuo, el desarrollo y progreso de la enfermedad periodontal serán muy diferentes, por lo que se con-

* $\quad$ Máster de Periodoncia. Universidad Complutense de Madrid.

** Licenciado en Odontología. Universidad de Firenze, Italia. Doctorando Universidad Complutense de Madrid.

*** Doctorando Universidad Complutense de Madrid. 
sidera que esta enfermedad tiene un origen multifactorial.

Todavía hoy existen ciertos aspectos sin resolver acerca de las características clínicas de la enfermedad periodontal. Se desconoce porqué esta patología tiene tendencia a progresar según un patrón localizado en algunos individuos, porqué existe una propensión a la destrucción periodontal bilateralmente simétrica o por qué el desarrollo no es lineal sino a base de episodios de actividad seguidos de periodos de remisión. Incluso con respecto a por qué algunos individuos desarrollan una periodontitis a partir de una gingivitis mientras que otros se mantienen en la fase inicial, no existe una respuesta detallada. Las variaciones clínicas que se producen son consecuencia de las diferencias en el tipo y cantidad de agentes infecciosos así como en factores asociados a la respuesta del huésped y en este sentido pueden existir elementos aún por determinar que jueguen un papel importante en la etiología y desarrollo de esta enfermedad.

Desde mediados de la década de los 90 , se está estudiando el posible efecto que los virus de la familia herpes podrían tener sobre el inicio y desarrollo de la enfermedad periodontal. En particular, el citomegalovirus humano (CMVH) así como el virus Epstein-Barr (VEB) parecen tener un papel especialmente relevante en la etiopatogénesis de determinadas formas graves de la enfermedad que nos ocupa. El genoma de estos virus se encuentra frecuentemente y en grandes proporciones en periodontitis progresivas en adultos, periodontitis agresivas tanto generalizadas como localizadas, gingivitis ulceronecrotizante aguda, abscesos periodontales y algunos tipos raros de periodontitis avanzadas asociadas a enfermedades sistémicas.

El objetivo de esta revisión es presentar la evidencia disponible sobre el papel de los virus en el inicio y desarrollo de la periodontitis. Se describirá brevemente la estructura y mecanismo de acción de los virus, la patogénesis de los mismos dentro del marco de la enfermedad periodontal y finalmente se presentarán brevemente algunos de los artículos que han llevado a asociar los virus con la enfermedad periodontal.

\section{VIRUS: CARACTERÍSTICAS GENERALES Y MECANISIMO DE INFECCIÓN}

Los virus constituyen una clase de agentes infecciosos única en biología. Son parásitos intracelulares obligados ya que son metabólicamente inertes fuera de la célula del hospedador. Por esta razón, aunque presentan propiedades de organismos vivientes como tener un genoma y la capacidad de replicación, no se deben de considerar microorganismos.

La partícula vírica o virión puede considerarse un bloque de material genético capaz de replicación autónoma, rodeado de una capa proteica (nucleocápside) $y$, a veces, de una cubierta membranosa (bicapas lipídicas y proteínas) adicional que lo protege del medio ambiente y sirve de vehículo para su transmisión desde una célula huésped a otra.

Se conocen más de 30.000 virus diferentes capaces de infectar vertebrados, invertebrados, plantas o bacterias. Se agrupan en 3.600 especies, 71 familias y 164 géneros. Poco más de 40 se consideran de importancia médica en humanos. Son la causa de un amplio rango de enfermedades infecciosas y se han implicado en un $15-20 \%$ de neoplasmas malignos.

La clasificación de los virus es en base al tipo de ácido nucleico que constituye el genoma (ADN o ARN) que puede ser de cadena única o doble, a la presencia o ausencia de la cubierta membranosa y a otras características como la morfología del virión, su composición química o a la forma de replicación.

Los virus no tienen capacidad de producir energía, reproducir su propio genoma o sintetizar sus propias proteínas; consecuentemente su replicación depende de la energía del huésped.

En su proceso de multiplicación, el virus pasa por diferentes fases:

a) Adsorción a la célula del huésped.

b) Penetración o entrada.

c) Rotura de la cubierta para liberar el genoma.,

d) Producción de los componentes del virión.

e) Ensamblaje y

f) Liberación de la célula.

El primer paso en toda la infección viral es la unión o adsorción de la partícula infecciosa a la superficie celular. Un requisito es la colisión entre el virión y la célula, visto que los virus no tienen capacidad mótil. Ésta es una reacción muy específica entre proteínas de unión del virión y receptores de la célula del huésped. La unión proteína receptor permite al virus de penetrar su membrana y al mismo tiempo perder la cubierta membranosa de forma que solo el nucleocápside pasa al citoplasma celular. El siguiente paso es la 
producción de mRNA específicos para el virus, que programan a los ribosomas celulares para sintetizar proteínas virales. Además de las proteínas estructurales del virión, los virus deben dirigir la síntesis de enzimas y otras proteínas especializadas necesarias para la replicación del genoma, ensamblaje y liberación del virus. Tras la fase de replicación que aprovecha las polimerasas de ADN celulares, el siguiente proceso consiste en encerrar el nuevo genoma viral en una cápside de proteínas que se conoce como ensamblaje o encapsidación. Gracias a lisozimas o peptidasas que debilitan la pared celular finalmente el virus escapa de la célula infectada.

\section{HERPESVIRUS}

El grupo de los herpesvirus, de la familia Herpesviridiae, está constituido por grandes virus de $A D N$ de doble banda cubiertos que se encuentran tanto en los animales como en el hombre. Están diseminados por toda la naturaleza y producen infecciones que varían entre úlceras cutáneas dolorosas hasta varicela y encefalitis.

De la familia Herpesviridiae son ocho los miembros capaces de infectar al hombre: dos virus del herpes simple (HSV-1 y HSV-2), citomegalovirus (CMVH), virus de varicela y zoster (VZV), virus de Epstein-Barr (VEB), herpes virus 6 humano (HHV-6) y los recién descubiertos herpesvirus humanos tipos 7 y 8 (HHV-7, HHV-8). Con base a ciertas semejanzas virológicas de tropismo de tejido, patogenicidad y comportamiento ante cultivo en laboratorio, los virus de la familia herpes se pueden dividir en tres subfamilias: $\alpha, \beta$ y $\gamma$. Los alpha-hepesvirus presentan un ciclo rápido de replicación y son neurotrópicos mientras que los virus herpesvirus $\beta$ y $\gamma$ se diferencian por la dimensión del genoma y de la estructura y porque se replican más lentamente y principalmente en células linfáticas o de origen glandular.

Desde el punto de vista morfológico todos los herpesvirus son semejantes, con un tamaño global de 180 a $200 \mathrm{~nm}$. El núcleo está rodeado por una cápside icosaédrica sobre la cual se encuentra una región llena de proteínas que se denomina tegumento. La partícula viral está cubierta por una envoltura lipoprotéica derivada de la membrana nuclear del huésped.

Todos estos agentes producen una infección inicial seguida por un periodo de infección latente, durante el cual el genoma viral se encuentra en las células y se conserva como epitoma. En estas condiciones demuestra una limitada necesidad de expresión de genes específicos para conservar el estado de latencia. Cuando se produce la reactivación del virus a causa de interacciones complejas de éste con el sistema inmune del huésped es cuando se obtendrá por resultado la enfermedad recurrente. Pero en general, las enfermedades por herpesvirus están limitadas a pacientes jóvenes con un sistema inmunológico todavía inmaduro o a pacientes inmuno-deprimidos.

En esta revisión se hace particular énfasis en los herpesvirus y concretamente en el citomegalovirus humano (CMVH) así como en el virus de Epstein-Barr (VEB) en cuanto parecen tener un papel especialmente relevante en la etiopatogénesis de determinadas formas graves de la enfermedad periodontal.

\section{HERPESVIRUS EN ENFERIMEDAD PERIODONTAL}

Tal y como ocurre con la relación entre las bacterias y la enfermedad periodontal, la asociación entre herpesvirus y periodontitis agresivas se puede estudiar mediante los criterios de causalidad de Hill. Según Hill, para que exista una relación causal entre un posible factor de riesgo y una patología es necesario que se cumplan ocho postulados que se revisarán individualmente y que ayudarán a determinar el papel que los virus pueden tener en el progreso de la periodontitis.

\section{FUERZA DE ASOCIACIÓN}

Las asociaciones fuertes suelen ser causales con mayor probabilidad que las débiles. Se ha demostrado que existe una asociación significativa entre VHS, CMVH, VEB-1, VEB-2 y VHH-7 y periodontitis, cuando se compara la presencia de estos virus en localizaciones sanas y lesiones periodontales de los mismos individuos (Contreras y cols. 2000).

Sin embargo, la relación más fuerte se produce entre CMVH y EBV y periodontitis agresivas. En un estudio realizado sobre 16 pacientes con periodontitis agresiva se observó una relación significativa con los virus antes mencionados tanto de forma individual como asociados. De hecho, la coinfección CMVH-EBV se asoció siempre a aquellas localizaciones que sangraban al sondaje y mostraban, de media, un ritmo de progresión más rápido que aquellas localizaciones en las que únicamente se aisló a uno de los dos virus (Kamma y 
cols. 2001). Los resultados de este estudio están en concordancia con otros estudios en los que también se observa una relación entre periodontitis agresiva y CMVH y EBV sobretodo si los dos virus se hallan asociados (Yapar y cols. 2003).

La acción sinérgica de varios virus no es la única descrita en este campo. La presencia de CMVH y EBV también se asocia a una mayor presencia de determinadas bacterias periodontopatógenas. En el estudio de Kamma mencionado anteriormente, se observa que la presencia de los virus se asocia a la de $P$. gingivalis y $D$. pneumosintes cuya coinfección también se relacionó con aquellas localizaciones sangrantes. Asimismo, la odds ratio de sufrir una enfermedad periodontal agresiva se multiplica cuando a la presencia de CMVH se asocia a la de $P$. gingivalis (Odds ratio $=51.4$ ) en una población de adolescentes jamaicanos (Michalowicz y cols 2000). Finalmente, parece que la activación de $\mathrm{CMVH}$ junto con la presencia de $A$. actinomycetemcomitans constituye un rasgo patogénico importante en las lesiones periodontales agresivas (Slots y cols. 1991).

Haciendo referencia a los procesos agudos de la enfermedad periodontal, también se ha encontrado relación entre la gingivitis ulceronecrotizante (GUNA) y la presencia de CMVH. En una población de niños entre 3 y 14 años de Nigeria, se encontró una gran correlación entre la presencia de CMVH y otros virus y GUNA en niños con malnutrición. Estos resultados contrastaban con los obtenidos en niños que no presentaban GUNA sufriesen o no malnutrición (Contreras y cols. 1997).

Puesto que los virus se pueden encontrar tanto activos como en estado latente, se estudió si existía alguna relación entre la activación de CMVH y localizaciones enfermas estables 0 activas. Se seleccionaron 11 pacientes con periodontitis agresiva juvenil de entre 10 y 23 años. Todos aquellos individuos que sufrían procesos tempranos (10-14 años) presentaban CMVH activo en las bolsas profundas, mientras que solo uno de los tres pacientes mayores de 14 años, y ninguna de las bolsas superficiales, presentaban CMVH activo. Además, la presencia de la forma activa del virus se asoció a aquellas localizaciones donde radiológicamente no se observaba la lámina dura de la cresta alveolar, un signo de posible progresión de la enfermedad periodontal (Ting y cols. 2000).

Finalmente, los pacientes con VIH suelen sufrir procesos periodontales más agresivos que los pacientes no VIH aunque no en todos los casos. Esta diferencia pue- de ser debida a la mayor presencia de herpesvirus en la mayoría de los pacientes VIH debido a la inmunosupresión que dicha enfermedad conlleva (Contreras y cols. 2001). El CMVH se encontró en un $81 \%$ de los pacientes HIV que sufrían periodontitis y fue el virus más frecuentemente aislado (Contreras y cols 2001). Los otros virus aislados con mayor frecuencia en este tipo de pacientes son el EBV-2 y el HVH-8 o virus del sarcoma de Kaposi. El EBV-2 se halló en un 57\% de las biopsias de las lesiones periodontales de pacientes, mientras que el HVH-8 se encontró en un $24 \%$ de los pacientes con VIH y periodontitis (Contreras y cols. 2001).

\section{CONSISTENCIA DE LAA ASOCIACIÓN}

Este postulado hace referencia a la observación repetida de una asociación en poblaciones diferentes y con otras circunstancias medioambientales distintas. En la última revisión publicada acerca del papel de los virus en la enfermedad periodontal (Slots 2005) se muestran todos aquellos estudios en los que se valora la presencia de CMVH, EPV y VHS en pacientes periodontales de diferentes países (tabla 1). Todos los estudios citados describen una prevalencia alta de herpesvirus en lesiones periodontales lo cual da fuerza a la asociación entre ambas variables.

\section{ESPECIFICIDAD}

Este criterio requiere que una causa conduzca a un único efecto, no a efectos múltiples. Sin embargo, empíricamente se demuestra que causas únicas conducen a efectos múltiples y por tanto es un criterio actualmente en controversia y no aplicable en el caso de los virus y la enfermedad periodontal destructiva puesto que los virus actúan a muchos niveles causando diferentes patologías.

\section{TEIMIPORALIDAD}

Se refiere a que necesariamente la causa debe preceder al efecto y nunca al revés. El propio Hill concluye que aunque ninguno de sus postulados es incontestable ni requerido como sine qua non, éste es el que se debe cumplir para demostrar la relación entre dos factores como causa y efecto.

La transmisión de virus puede ocurrir tanto verticalmente de la madre al hijo como horizontalmente por 


\begin{tabular}{|c|c|c|c|c|c|}
\hline \multicolumn{6}{|c|}{$\begin{array}{c}\text { TABLA 1.- PREVALENCIA DE HERPESVIRUS EN PACIENTES PERIODONTALES } \\
\text { DEVARIOS PAÍSES }\end{array}$} \\
\hline Estudio & País & $\begin{array}{l}\text { Estado } \\
\text { periodontal }\end{array}$ & $\begin{array}{l}\text { Virus herpes } \\
\text { simple Tipo I }\end{array}$ & Virus Epstein-Barr & Citomegalovirus \\
\hline $\begin{array}{l}\text { Contreras } \\
\text { y cols. }(2000)\end{array}$ & EE.UU & $\begin{array}{l}\text { Periodontitis } \\
\text { crónica } \\
\text { avanzada }\end{array}$ & $\begin{array}{l}57 \% \text { periodontitis } \\
9 \% \text { sanos/ligera } \\
\text { gingivitis }\end{array}$ & $\begin{array}{l}79 \% \text { periodontitis } \\
27 \% \text { sanos/ligera } \\
\text { gingivitis }\end{array}$ & $\begin{array}{l}86 \% \text { periodontitis } \\
18 \% \text { sanos/ligera } \\
\text { gingivitis }\end{array}$ \\
\hline $\begin{array}{l}\text { Ting y cols. } \\
(2000)\end{array}$ & EE.UU & $\begin{array}{l}\text { Periodontitis } \\
\text { agresiva } \\
\text { localizada }\end{array}$ & $\begin{array}{l}55 \% \text { periodontitis } \\
9 \% \text { sanos }\end{array}$ & $\begin{array}{l}64 \% \text { periodontitis } \\
18 \% \text { sanos }\end{array}$ & $\begin{array}{l}73 \% \text { periodontitis } \\
18 \% \text { sanos }\end{array}$ \\
\hline $\begin{array}{l}\text { Michalowicz } \\
\text { y cols. }(2000)\end{array}$ & Jamaica & $\begin{array}{l}\text { Periodontitis } \\
\text { localizada }\end{array}$ & Sin datos & $\begin{array}{l}33 \% \text { agresiva } \\
45 \% \text { incipiente } \\
17 \% \text { sano/gingivitis }\end{array}$ & $\begin{array}{l}73 \% \text { agresiva } \\
40 \% \text { incipiente } \\
22 \% \text { sano/gingivitis }\end{array}$ \\
\hline $\begin{array}{l}\text { Kamma y cols. } \\
(2001)\end{array}$ & Grecia & $\begin{array}{l}\text { Periodontitis } \\
\text { generalizada }\end{array}$ & $\begin{array}{l}35 \% \text { E.P. activa } \\
9 \% \text { E.P. estable }\end{array}$ & $\begin{array}{l}44 \% \text { E.P. activa } \\
13 \% \text { E.P. estable }\end{array}$ & $\begin{array}{l}59 \% \text { E.P. activa } \\
13 \% \text { E.P. estable }\end{array}$ \\
\hline $\begin{array}{l}\text { Saygun y cols. } \\
(2004)\end{array}$ & Turquía & $\begin{array}{l}\text { Periodontitis } \\
\text { generalizada }\end{array}$ & $\begin{array}{l}78 \% \text { agresivas } \\
0 \% \text { sanos }\end{array}$ & $\begin{array}{l}72 \% \text { agresivas } \\
6 \% \text { sanos }\end{array}$ & $\begin{array}{l}72 \% \text { agresivas } \\
0 \% \text { sanos }\end{array}$ \\
\hline $\begin{array}{l}\text { Kubar y cols. } \\
(2005)\end{array}$ & Turquía & $\begin{array}{l}\text { Periodontitis } \\
\text { generalizada }\end{array}$ & Sin datos & $\begin{array}{l}89 \% \text { agresivas } \\
49 \% \text { crónicas }\end{array}$ & $\begin{array}{l}78 \% \text { agresivas } \\
46 \% \text { crónicas }\end{array}$ \\
\hline $\begin{array}{l}\text { Ling y cols. } \\
(2004)\end{array}$ & Taiwan & $\begin{array}{l}\text { Periodontitis } \\
\text { crónica }\end{array}$ & $31 \%$ & $4 \%$ & $52 \%$ \\
\hline $\begin{array}{l}\text { Li y cols. } \\
(2004)\end{array}$ & China & $\begin{array}{l}\text { Periodontitis } \\
\text { crónica }\end{array}$ & Sin datos & $\begin{array}{l}58 \% \text { E.P. activa } \\
23 \% \text { quiescent } \\
19 \% \text { gingivitis }\end{array}$ & Sin datos \\
\hline $\begin{array}{l}\text { Idesawa y cols. } \\
(2004)\end{array}$ & Japón & $\begin{array}{l}\text { Periodontitis } \\
\text { crónica }\end{array}$ & Sin datos & $\begin{array}{l}49 \% \text { periodontitis } \\
15 \% \text { sanos }\end{array}$ & Sin datos \\
\hline
\end{tabular}

contacto directo persona-persona. Desde el nacimiento el individuo es portador de virus que se mantendrán en estado de latencia hasta que algún estímulo provoque la activación de los mismos. Dicha activación será o no sintomática en función del estado inmunológico del individuo. Queda por determinar todavía si la reactivación del virus es la causa de la enfermedad periodontal o si por el contrario la actividad producida por el estimulo infeccioso propio de la enfermedad es lo que provoca la reactivación del virus (Slots 2005).

\section{Gradiente biológico}

Se constataría por la presencia de una relación dosisefecto uniformemente creciente o decreciente. Esto no siempre es posible demostrarlo y otras veces aunque se produzca se debe al azar. Prácticamente todos los artículos publicados acerca del tema que nos ocupan utilizan la técnica del nested $P C R$, sin embargo esta técnica ofrece sólo datos cualitativos. Únicamente existen dos artículos que hayan utilizado las nuevas técnicas de PCR cuantitativa capaces de aportar datos acer- 
ca del efecto que la cantidad de virus tiene sobre el progreso de la enfermedad (Kubar 2004, 2005). Ambos estudios demuestran una asociación positiva entre la cantidad de CMVH y EPV y la gravedad de la enfermedad. Los dos virus se hallaron en mayor proporción en aquellas localizaciones pertenecientes a pacientes con periodontitis agresivas que en pacientes con periodontitis crónicas (Kubar 2005). Por otra parte, a diferencia de lo observado por otros estudios, al utilizar PCR cuantitativa no se pudo observar la presencia de CMVH en ninguna de las localizaciones sanas (Kubar 2004).

\section{Pliausibinimad biológica}

El fenómeno (enfermedad) tiene que estar producido por el factor a estudio siguiendo las bases fisiopatológicas conocidas. Los virus afectan al sistema inmunológico del huésped desde muchos frentes al invadir las células que participan en el proceso inflamatorio. Su acción sobre dichas células desencadena una serie de reacciones capaces de conducir a la destrucción periodontal.

\section{Coherencia}

Los postulados nunca pueden contradecir los conocimientos universales que se tengan de esa enfermedad. La enfermedad periodontal destructiva puede presentar un grupo heterogéneo de cuadros caracterizados por la presencia de agentes infecciosos específicos que actúan sobre un huésped cuyas defensas locales son inadecuadas. La frecuencia con la que se encuentran virus en lesiones periodontales, junto con el conocimiento de su naturaleza infecciosa sobre las células encargadas del proceso inflamatorio así como del regenerativo hacen posible la creencia de la existencia de una periodontitis asociada a herpesvirus (Slots 2005).

\section{EVIDENCIA EXPERIMIENTAL DE DISMINUCIÓN O DESAPARICIÓN DEL EFECTO CUANDO SE SUPRIME LA CAUSA}

No siempre es factible tener esa evidencia, especialmente en enfermedades de etiología multifactorial. Es una prueba de causalidad que no está exenta de sesgos de investigación cuando hay factores de confusión. Se ha demostrado que la terapia antimicrobiana es capaz de reducir significativamente la presencia de herpesvirus en el periodonto debido a que la persis- tencia de los mismos depende de la presencia de las células inflamatorias gingivales (Saygun y cols. 2002, 2004 y Pacheco y cols. 2002). Se desconoce sin embrago, si la eliminación de herpesvirus se traduce en una mayor capacidad de cicatrización que si solamente se eliminasen las bacterias. De todas formas, el hecho de que el tratamiento periodontal junto con medidas de higiene oral repetidas sean acciones capaces de reducir la cantidad de CMVH y EBV hasta niveles indetectables, ayuda a controlar la transmisión de dichos virus entre individuos y posiblemente las enfermedades orales asociadas a su presencia (Saygun y cols 2005 y Idesawa y cols. 2004).

\section{AnAlogía}

Si es verdad que los factores a estudio son la causa del fenómeno visto, es lógico suponer que situaciones parecidas darán efectos parecidos. Los virus de la familia herpes forman parte de la etiología de múltiples enfermedades siguiendo un patrón etiopatológico similar al expuesto en esta revisión para el caso de la periodontitis.

\section{PAPEL ETIOPATOGÉNICO EN LA ENFERIMIEDAD PERIODONTAL}

La literatura evidencia como la destrucción de los tejidos periodontales ocasiona más frecuentemente y progresa más rápidamente en localizaciones infectadas por herpesvirus. Se piensa que los virus actúan sobre el huésped de forma directa e indirecta. Lo hacen directamente como resultado de la infección y siguiente replicación, o de forma indirecta como consecuencia de un desequilibrio en las defensas del hospedador que puede favorecer una agresión por parte de la flora bacteriana comensal.

Los herpesvirus pueden causar un efecto citotóxico directo sobre los fibroblastos, queratinocitos, células endoteliales, inflamatorias y posiblemente osteoblastos. Las capacidades fagocíticas y bactericidas de los linfocitos polimorfonucleares se observan significativamente reducidas si se ven infectadas por herpesvirus (Ongradi y cols). Por otra parte, los fibroblastos infectados demuestran un recambio y capacidad de reparación reducidos (Smith y cols.).

Otra de las posibles vías etiopatogénicas que apoyarían la existencia de una periodontitis asociada a virus, es la relación positiva que se ha encontrado entre 
la infección por herpesvirus y el sobrecrecimiento de bacterias periodontopatógenas. Así la presencia subgingival de HCMV o EBV-1 se relaciona con una elevada incidencia de Porphyromonas gingivalis, Tannerella forsythia, Dyalister pneumosintes, Prevotella intermedia, Campylobacter rectus y Treponema denticola (Saygun y cols, Slots y cols 2003 230, Slots 2002 Contreras 1999 y cols.). Por otra parte, estudios en Finlandia y Rusia han observado una asociación positiva entre niveles de anticuerpos anti Porphyromonas gingivalis y Actynobacillus Acinomycetemcomitans (A.a.) y anticuerpos anti HSV (Vilkuna y cols.). Finalmente, Teughels y cols. observaron una mayor capacidad de adhesión (70\%) de A.a. a células epiteliales infectadas por HCMV.

Los herpesvirus también actúan a través del papel que juegan en el sistema de defensa del huésped, siendo capaces de alterar tanto la respuesta celular como la humoral. Pueden influir en la producción de citoquinas, modulando de esta manera la respuesta inmune del huésped frente al ataque viral (Mogenesen y cols.). Además, la infección por HCMV aumenta la secreción de Il-1 $\beta$, Il-6, TNF $\alpha$, monocitos y macrófagos, alimentando de esta manera la respuesta anti-inflamatoria (Mogenesen y cols.,Wara-aswapati $\mathrm{N} \mathrm{y} \mathrm{cols.)} \mathrm{El} \mathrm{aumento}$ de producción de citoquinas actúa de forma sinérgica con el aumento provocado por el lipopolisacárido de las bacterias gram-negativas (Wara-aswapati $\mathrm{N}$ y cols).

Por su parte, el EBV se considera un potente activador de la proliferación policlonal de los linfocitos $\mathrm{B}$, induciendo la proliferación y diferenciación de células secretoras de inmunoglobulinas. Tanto el aumento de la concentración gingival de determinada citoquinas como la proliferación policlonal de los linfocitos B, son características asociadas con una progresión más rápida de la enfermedad periodontal (Gemmel E y cols, Page y cols).

Con respecto al HCMV, éste ha demostrado alterar la respuesta inmune celular, favoreciendo un aumento de los linfocitos T CD8 positivos (Wikby y cols., Sester y cols.) lo cual también se ha evidenciado en formas agresivas de periodontitis (Mathur y cols, Kinane y cols.).

En resumen, se ha visto como las infecciones por herpesvirus pueden actuar a varios niveles en el mecanismo etiopatogénico de la enfermedad periodontal. Se han demostrado efectos citotóxicos directos sobre fibroblastos, osteoblastos y células inflamatorias así como indirectos a través de alteraciones de la respuesta tanto celular como humoral.
El daño tisular directo, el aumento de secreción de citoquinas catabólicas como la IL-1 la IL-6 y el TNF $\alpha$ o la activación policlonal de las células $B$ que favorece una respuesta humoral aumentada e inespecífica, pueden en parte justificar la relación entre infecciones por herpesvirus y las formas agresivas de Periodontitis.

A raíz de estos datos se ha formulado una hipótesis que trata de unir las distintas formas de periodontitis en una sola enfermedad que presenta un amplio espectro de manifestaciones clínicas, dependiendo de la presencia de una infección por herpesvirus y del sistema inmune del paciente. De esta manera, en un extremo se encontrarían pacientes inmunocompetentes con una enfermedad periodontal crónica, cuya progresión, a base de episodios de actividad seguidos de periodos de remisión, podría ser compatible con fases de latencia o reactivación del virus. Mientras que en el otro extremo estarían los pacientes inmunodeprimidos, cuya función reducida se manifiesta clínicamente con formas rápidamente destructivas de periodontitis. Entre los dos extremos se encontrarían las formas intermedias que dependen de un sutil equilibrio entre las defensas del organismo y los agentes patógenos bacterianos y virales (Slots 2005).

\section{CONCLUSIONES}

Hasta la fecha, las bacterias se han considerado indispensable para el desarrollo de periodontitis y su interacción con el huésped es la base de la etiopatogenia de esta enfermedad. Sin embargo, existen características clínicas en algunos cuadros de la enfermedad periodontal que la mera presencia de bacterias no es capaz de explicar. Las razones por las cuales la periodontitis sigue un patrón localizado en algunas personas, existe una simetría bilateral de las lesiones, la enfermedad progresa a brotes o algunas gingivitis no progresan a periodontitis, son cuestiones que la hipótesis de una etiología virus-bacterias sí que podría resolver. La lesión combinada podría causar un daño directo a los tejidos periodontales o bien alterar las resistencias del periodonto de forma que se facilitase el sobre crecimiento de bacterias periodontopatógenas a nivel subgingival (Slots y cols. 2001).

En esta revisión se ha tratado de analizar la relación entre virus y periodontitis a través de los criterios de causalidad de Hill. La mayoría de los postulados sugiere que dicha asociación podría ser posible, sin embargo, el criterio más importante, el de temporali- 
dad, no ha sido demostrado científicamente. El hecho de que la periodontitis sea una patología multifactorial, no reproducible de forma experimental y con un largo periodo de latencia, hace difícil establecer una relación causal entre esta enfermedad y los factores de riesgo que se asocian a su etiología.

Si se reconoce la posibilidad de un conexión entre la presencia de virus y periodontitis, posiblemente aumente el conocimiento que actualmente se tiene acerca de los mecanismos que llevan a la destrucción periodontal. Esto permitiría dar luz a cuestiones como el mecanismo molecular de la enfermedad o la diferencia entre lesiones periodontales estables y activas. La realización de más estudios utilizando nuevos métodos de identificación y análisis posiblemente abra el camino a una nueva concepción de la etiología de esta interesante enfermedad.

\section{ABSTRACT}

The purpose of this review is to evaluate the evidence supporting the hypothesis that viral infection plays a role in the development of periodontitis. This relationship has been found mainly with the herpesvirus family, especially with human cytomegalovirus (CMV) and with Epstein-Barr virus (EBV), but also with human immunodeficiency virus (HIV).

The herpesvirus infection generally involves a mild or asymptomatic primary phase followed by an asymptomatic latent phase interrupted sporadically by periods of activation, where viral replication and possibly clinical disease become manifest and which will in part, explain the episodic progressive nature of human periodontitis. In fact, herpesvirus reactivation is triggered by a number of immunosuppressing factors, some of which have also been shown to be risk indicators of periodontal disease and which could relate both patologies.

\section{KEYWORDS}

Herpesviruses, cytomegalovirud, Epstein-Barr virus, periodontal disease, pathogenesis.

\section{BIBLIOGRAFÍA}

1. Contreras A, Falkler WA Jr, Enwonwu CO, Idigbe EO, Savage KO, Afolabi MB, Onwujwkwe D, Rams TE, Slots J.
Human Herpesviridae in acute necrotizing ulcerative gingivitis in children in Nigeria. Oral Microbiol Immunol 1997;12:259-65.

2. Contreras A, Umeda M, Chen C, Bakker I, Morrison Jl, Slots J. Relationship between herpesvirus and adult periodontitis and periodontopatic bacteria.J Periodontol 1999;70:478-84.

3. Contreras A, Nowzari H, Slots J. Herpesvirus in periodontal pocket and gingival tissue specimens. Oral Microbiol Immunol 2000;15:15-8.

4. Contreras A, Mardirossian A, Slots J. Herpesvirus in HIVperiodontitis. J Clin Periodontol 2001;28:96-102.

5. Gemmel E, Seymour GJ. Immunoregulatory control of TH1/TH2 cytokine profiles in periodontal disease. Periodontol 2000 2004;35:21-41

6. Idesawa M, Sugano N, Ikeda K, OshikawaM, Takane M, Seki K, Ito K. Dtection of Epstein-Barr virus in saliva by real-time PCR. Oral Microbiol Immunol 2004;19: 230-2.

7. Mogensen TH, Paludan SR. Molecular pathways in virusinduced cytokine production. Microbiol Mal Biol Rev 2001: 65;131-50.

8. Ongradi J, Sallay K, Kulcsar G. The decreased antibacterial activity of oral polymorfhonuclear luekocytes coincides with the occurrence of viruscarrying oral lymphocytes and epithelial cells. Folia Microbiol (Praha) 1987;32: 438-47.

9. Kamma JJ, Contreras A, Slots J. Herpes viruses and periodontopathic bacteria in early-onset periodontitis. J Clin Periodontol 2001;28:879-885.

10. Kinane DF, Johnston FA, Evans CW. Depressed helpertosuppressor T-cell ratios in early-onset forms of periodontal disease. ] Periodontal Res 1989;24:161-4.

11. Kubar A, saygun I, Özdemir A, Yapar M, Slots J. Realtime PCR quantification of cytomegalovirus in aggressive periodontitis lesions using TaqMan technology. J Periodontol Res 2004;39:81-6.

12. Kubar A, saygun I, Özdemir A, Yapar M, Slots J. Realtime PCR quantification of human cytomegalovirus and Epstein-Barr virus in periodontal pockets and the adjacent gingiva of periodontitis lesions. J Periodontal Res 2005;40:97-104. 
13. Li Y, Zhang YH, The association between infection of Epstein-Barr virus and chronic periodontitis (Chinese). Zhonghua Kou Qiang Yi Xue Za Zhi 2004;39:146-8.

14. Ling L-J, Ho C-C, Wu C-Y, Chen Y-T, Hung S-L. Association between human herpesvirus and the severity of periodontitis. J Periodontol 2004;75:1479-85.

15. Mathur A, Michalowicz BS. Cell-mediated immune system regulation in periodontal diseases. Crit Rev Oral Biol Med 1997;8:76-89.

16. Michalowicz BS, Ronderos M, camara-Silva R, Conterras A, Slots J. Human herpesvirus and Porphyromonas gingivalis are associated with early-onset periodontitis. $J$ Periodontol 2000;71:981-8.

17. Pacheco JJ, Coelho C, salazar F, Contreras A, Slots J, Velazco CH. Treatment of papillon-Lefevre syndrome periodontitis. J Clin Periodontol 2002;29:370-4.

18. Page RC, Offenbacher S, Schroeder HE, Seymour GJ, Kornman KS. Advances in the pathogenesis of periodontitis: summary of developments, clinical implications and future directions. Periodontol 2000 1997; 14:216-48.

19. Saygun I, Sahin S, Özdemir A, Kurtis B, Yapar M, Kubar A, Ozcan G. Dtection of human viruses in patients with chronic periodontitis and the relationship between viruses and clinical parameters. J Periodontol 2002; 73:1437-43.

20. Saygun 1, Kubar A, Ozdemir A, Yapar M, Slots J. Herpesviral-bacterial interrelationships in aggressive periodontitis. J Periodontal Res 2004;39:207-12.

21. Sester M, Sester U, Gartner BC, Gimdt M, Meyerhans A, Kfihler H. Dominance of virus-specific CD8 T cells in human primary cytomegalovirus infection. J Am Soc Nephrol 2002;13:2577-84.

22. Slots J, Schonfeld SE. Actinobacillus actinomycetemcomitans in localized juvenile periodontitis. In:Hamada S, Holt SC, McGhee RJ, editors. Periodontal disease:
Pathogens and Host Immune Responses. Tokyo: Quintessence Publishing Co., 1991;53-64.

23. Slots J, Sugar C, Kamma n. Cytomegalovirus periodontal presence is associated with subgingival Dialister pneumosintes and alveolar bone loss. Oral Microbiol Immuno/2002;17: 369-74.

24. Slots J, Kamma n, Sugar C. The herpesvirus-Porphyromonas gingivalis-periodontitis axis.J Perioodontal Res 2003;38:318-23.

25. Slots J. Hepesvirus in periodontal disease. Periodontology 2000 2005;38:33-62.

26. Smith MacDonald E, Nowzari H, Contreras A, Flynn J, Morrison Jl, Slots J. Clinical and microbiological evaluation of a bioabsrbable and a nonresorbable barrier membrana in the treatment of periodontal infraosseous lesions. J Periodontol 1998;69:445-53.

27. Teughels W, Vanranst M, Pauwels M, Dierickx K, van Steenberghe D, van Eldere J, Quirynen M. Effects of human cytomegalovirus infection on epithelial adhesion by periodontopathogens. Paneuropean IADR, 2002.

28. Ting M, Contreras A, slots J. Herpesvirus in localized juvenile periodontitis. J periodontol Res 2000;35:17-25.

29. Vilkuna-Rautiainen T, Pussinen PJ, Roivainen M, Petays T, Jousilahti P, Hovi T, Asikainen S, Vartiainen E. Herpes simplex infections in relation to periodontitis in Finland and in Russia. J Dent Res 2002;81 (Spec Iss A):A372 (Abstract 2986).

30. Wara-aswapati N, Boch JA, Auron PE. Activation of interleukin $1 \sim$ gene transcription by hurnan cytomegalovirus - Molecular mechanisms and relevance 10 periodontitis. Oral Microbiol Immunol 2003;18:67-71.

31. Wikby A, Johansson B, Olsson J, L6fgren S, Nilsson BO, Ferguson F. Expansions of peripheral blood CD8 Tlymphocyte subpopulations and an association with cytomegalovirus seropositivity in the elderly: the Swedish NONA immune study. Exp Gerontol 2002: 37: 445-53. 
